\title{
O ensino médio brasileiro em questão: integração curricular e formação de professores
}

\author{
Helenice Aparecida Bastos Rocha* \\ Marcelo de Souza Magalhães**
}

\section{Resumo}

Este artigo analisa as proposições de reformulação do ensino médio no Brasil, abordando a proposta de integração curricular como uma questão para a implantação de um novo ensino médio. A integraçáo curricular vem sendo perseguida desde os primeiros documentos de organização do ensino médio produzidos na década de 1990 entre diretrizes, pareceres e a própria Lei de Diretrizes e Bases, até chegar às novas Diretrizes Curriculares Nacionais do Ensino Médio de 2012. O texto esquadrinha o percurso de construção da integração curricular como uma meta e as principais noçôes que a sustentam. Compreende-se que a integração curricular pretendida, bem como seus alicerces, requerem algumas condiçóes que propiciam mudanças na formação inicial e continuada de professores, entre elas alteraçôes estruturais nos tempos e espaços da escola e do professor, bem como uma reflexão consistente e crítica sobre esse conjunto de ideias no âmbito das instituiçóes formadoras de professores, proporcionando o estabelecimento de novos cursos para essa formação.

Palavras-chave: Ensino Médio. Interdisciplinaridade. Formação de Professores

\footnotetext{
* Doutora em Educação pela Universidade Federal Fluminense (UFF). Professora do Departamento de Ciências Humanas da Universidade do Estado do Rio de Janeiro (UERJ). ** Doutor em História pela Universidade Federal Fluminense (UFF). Professor do Departamento e da Pós-Graduação em História na Universidade Federal do Estado do Rio de Janeiro (UNIRIO).
} 
A portaria ministerial $\mathrm{n}^{\circ} 1.140$, de 22 de novembro de 2013, assinada pelo então ministro da Educação Aloizio Mercadante, regulamentou o Pacto Nacional pelo Fortalecimento do Ensino Médio (BRASIL, 2013). Três dias depois, em Brasília, o ministro e seus assessores lançaram o Pacto, por meio de uma coletiva de imprensa. Trata-se, nas palavras de Mercadante (2013), de uma dentre "um conjunto de açôes para superar os grandes desafios do ensino médio brasileiro". Porém, no que consiste o Pacto?

O Pacto consiste em uma política de formação continuada voltada para os professores e os coordenadores pedagógicos que atuam nas salas de aula das escolas das redes estaduais e do Distrito Federal. O que equivale, em 2012, a 20.317 escolas e um público alvo de 495.697 professores. A opçáo pelas redes estaduais deve-se ao fato de concentrarem quase $85 \%$ das matrículas do ensino médio, são 7.111 .741 de um total de 8.376 .852 de matrículas, números referentes ao censo escolar de 2012.

Lançado no final de 2013, tendo sido preparadas há pelo menos um ano, as açóes previstas no Pacto estão em pleno funcionamento na atualidade. Seus objetivos, explicitados no artigo $4^{\circ}$ da portaria ministerial, são:

I - contribuir para o aperfeiçoamento da promoção dos professores e coordenadores pedagógicos do ensino médio;

II - promover a valorização pela formação dos professores e coordenadores pedagógicos do ensino médio;

III - rediscutir e atualizar as práticas docentes em conformidade com as Diretrizes Curriculares Nacionais do Ensino Médio - DCNEM. (BRASIL, 2013).

Para além da melhoria do espaço escolar, visando torná-lo um lugar agradável para se aprender, o foco da política pública é o professor que está na escola e que é o principal responsável pelo sucesso ou fracasso da implementação do disposto nas Diretrizes Curriculares Nacionais do Ensino (DCNEM). Nas palavras de Mercadante (2013), o foco está voltado para o professor que "come pó de giz", que está em sala de aula. Reafirmando, o professor é fundamental para o sucesso ou o fracasso de qualquer tipo de política pública voltada para a Educaçáo. O ministério tem clareza sobre esse ponto, como se pode perceber na apresentaçáo do Pacto feita por Mercadante (2013): “[...] urge definir um programa de formação de professores do ensino médio com propostas viáveis 
para iniciar um processo de rediscussão das práticas docentes à luz das diretrizes curriculares para a formação da juventude do País".

O Ministério da Educação (MEC) parece ter apreendido essa necessidade com as diversas experiências de implementação de políticas públicas para o ensino médio desde a redemocratização do País. Em 2014, já se vão dezesseis anos, três presidentes da República e seis ministros da Educação, desde a instituição das Diretrizes Curriculares Nacionais do Ensino Médio - Resolução CEB/CNE no 3, de 26 de junho de 1998 (BRASIL, 1998b). Durante esse período, em conformidade com tais Diretrizes, foram divulgadas três versōes dos Parâmetros Curriculares Nacionais para o Ensino Médio (PCNEM).

A primeira versão, de 1999, buscando superar a lógica disciplinar presente nas escolas, propunha organizar o ensino médio em três áreas: Linguagens, códigos e suas tecnologias, Ciências da Natureza, Matemática e suas tecnologias e Ciências Humanas e suas tecnologias (BRASIL, 1999). Tanto as Diretrizes como os Parâmetros foram organizados a partir das áreas de conhecimento e da definição de competências e habilidades a serem desenvolvidas pelos alunos ao longo do processo de ensino-aprendizagem.

O compromisso presente em ambos os textos era com os quatro alicerces estruturadores da educação: aprender a conhecer, aprender a fazer, aprender a viver e aprender a ser. Tais alicerces são oriundos do Relatório da Comissão Internacional sobre a Educação para o século XXI, da UNESCO, e foram incorporados à Lei de Diretrizes e Bases da Educação Nacional - Lei no 9.394/96 (BRASIL, 1996).

As Diretrizes e os PCNEM praticamente não fazem menção aos conteúdos a serem trabalhados nos anos do Ensino do Médio, listando apenas as competências e habilidades a serem desenvolvidas. Com a permanência da formação de professores em cursos de licenciatura com a configuração disciplinar (português, matemática, química, física, história, geografia...) e a ênfase em conteúdos factuais ou conceituais, os professores, em sua grande maioria, não tiveram instrumentos para implementar as áreas de conhecimento, o que exigiria investir na construção de um ensino-aprendizagem fundamentado, sobretudo, no diálogo interdisciplinar.

Em 2002, passados três anos da primeira versão dos Parâmetros e último ano de governo de Fernando Henrique Cardoso, foram publicados os 
PCN+Ensino Médio (BRASIL, 2002), cada uma das áreas de conhecimento presentes nas DCNEM e nos PCNEM de 1999 ganhou um volume de orientaçôes educacionais complementares. Esta versão mais detalhada das áreas surgiu como resposta às críticas feitas ao PCNEM de 1999, havendo um significativo investimento no sentido de convencer o professor que atuava no ensino médio da qualidade da proposta e da vantagem em adotá-la. Fundamentalmente, procurava-se mostrar caminhos para a constituição de um diálogo interdisciplinar no espaço escolar. Ou seja, caminhos para tirar do papel a proposiçẫo das áreas de conhecimento.

Em 2004, após cinco anos da primeira versão dos Parâmetros e no segundo ano de governo de Luís Inácio Lula da Silva, retomou-se a discussão dos PCNEM. O Ministério da Educação finalmente reconheceu a pouquíssima recepção que a proposta teve entre os professores do ensino médio. A retomada da discussão se deu a partir da divulgaçáo de documentos preliminares, escritos por especialistas, acerca do papel de cada disciplina no interior das áreas de conhecimento (BRASIL, 2004).

Após anos de discussões em torno das DCNEM de 1998 e das versóes dos PCNEM, foram aprovadas novas Diretrizes Curriculares Nacionais para o Ensino Médio - Resolução CEB/CNE no 2, de 30 de janeiro de 2012 (BRASIL, 2012b). Durante quatorze anos, muitas críticas foram feitas às políticas públicas voltadas para o ensino médio, como também, para as demais etapas da educação brasileira. Representantes do MEC, universidades, associações vinculadas à Educação (ANPED e ANFOPE, por exemplo), educadores brasileiros e membros do Conselho Nacional de Educação estiveram envolvidos em tais discussões. O debate sobre a educação, como bem sabemos, mobiliza enormes interesses e há muitos projetos em disputa.

Ao acompanhar as versôes, percebe-se que a formação inicial e continuada do professor, feita em cursos de licenciatura com lógicas disciplinares, acaba, na visão dos propositores de políticas públicas - de diferentes governos e vinculaçóes políticas e ideológicas -, sendo o calcanhar de Aquiles para o sucesso na implementação das áreas de conhecimento no ensino médio brasileiro.

As novas Diretrizes reafirmam o compromisso com a perspectiva interdisciplinar e mantém a organização do ensino médio por áreas do conhecimento, só que agora divididas em quatro ao invés de três: Linguagens, Matemática, Ciências Naturais e Ciências Humanas. As críticas constantes ao significado atribuído à palavra tecnologia presente nas DCNEM de 1998 
surtiram efeito, tendo sido retirada a palavra das denominaçóes dadas às áreas. Além disso, a Matemática, como linguagem base para muitas ciências, adquire status de área de conhecimento.

Outra preocupação importante nas DCNEM de 2012 é a indicação de quais disciplinas compóem cada área de conhecimento. O parágrafo único do artigo 10, define:

Em termos operacionais, os componentes curriculares obrigatórios decorrentes da LDB que integram as áreas de conhecimento são os referentes a:

I - Linguagens: a) Língua Portuguesa; b) Língua Materna, para populaçóes indígenas; c) Língua Estrangeira moderna; d) Arte, em suas diferentes linguagens: cênicas, plásticas e, obrigatoriamente, a musical; e) Educação Física.

II - Matemática.

III - Ciências da Natureza: a) Biologia; b) Física; c) Química.

IV - Ciências Humanas: a) História; b) Geografia; c) Filosofia; d) Sociologia. (BRASIL, 2012b).

As áreas de conhecimento são compreendidas como lugares importantes para a constituição de um diálogo entre os conhecimentos específicos de cada disciplina. Mais uma vez, há um reforço da interdisciplinaridade. Resta saber como construir essa interdisciplinaridade no espaço escolar. Com o lançamento do Pacto, no momento, a aposta feita pelo MEC é na formação continuada dos professores.

Esse curso de formação continuada é de 200 horas anuais e possui como eixo central o desenvolvimento da temática "Sujeitos do ensino médio e formação humana integral”. Organizado em duas etapas, a primeira é composta pelos seguintes campos temáticos: Sujeitos do ensino médio e formação humana integral; Ensino médio e formação humana integral; $\mathrm{O}$ currículo do ensino médio, seus sujeitos e o desafio da formação humana integral; Organização e gestão do trabalho pedagógico; Avaliação no ensino médio; e Áreas de conhecimento e integraçáo curricular. A segunda etapa do curso será voltada para o estudo das áreas de conhecimento, procurando reforçar os diálogos possíveis dentro das áreas e entre as áreas. 
A organização das etapas do curso e a perspectiva de uma formação humana integral tem claro objetivo de propiciar aos professores formas de implementar o disposto nas DCNEM de 2012, superando os entraves ocorridos nas tentativas anteriores. Nas palavras de Mercadante (2013), trata-se de um "curso de formação continuada composto por grupos de estudos, na escola, para aprofundamento e atualizaçáo de conceitos fundamentais que norteiam o ensino médio".

A nova tentativa de superação da dificuldade relativa à integração curricular no trabalho docente presente nessa iniciativa governamental nos leva a procurar compreender em que se alicerça essa proposta nos documentos base já mencionados, construindo seu percurso e suas linhas de força.

\section{Esquadrinhando a integração curricular nas DCNEM}

A integração curricular vem sendo perseguida desde os primeiros documentos de organizaçáo do ensino médio produzidos na década de 1990, com elementos a seu favor na Lei de Diretrizes e Bases da Educaçáo Nacional de 1996, nas Diretrizes Curriculares Nacionais do Ensino Médio de 1998, nos Parâmetros Curriculares Nacionais de 1999 e nos seus desdobramentos - versôes de 2002 e 2004 -, até chegar às novas Diretrizes Curriculares Nacionais do Ensino Médio de 2012.

Nas DCNEM de 2012, a busca dessa integração ocorre: na existência de um eixo integrador a partir de diferentes dimensôes; na articulação entre uma base comum nacional e uma parte diversificada dos conteúdos; na pretensão de diálogo entre disciplinas em áreas, tendo como eixo a interdisciplinaridade; na compreensão ampla sobre os componentes curriculares, que considera desde a manutençâo da organização disciplinar do conhecimento até uma reorganização, com a presença de componentes curriculares apresentados de forma não disciplinar.

Exporemos cada uma dessas estratégias, que visam a integraçáo curricular nas DCNEM de 2012, com destaque para a interdisciplinaridade e a busca de sua reiteração nos documentos citados, pois considerando as mudanças e as permanências, a integração entre disciplinas é o princípio e a estratégia indicada pelas legislaçóes e orientaçóes curriculares desde a década de 1990. Essa ênfase sobre a interdisciplinaridade vem sendo objeto de preocupaçáo de especialistas do "ensino de" pela pouca clareza acerca do papel pretendido para as disciplinas escolares no novo arranjo curricular do ensino médio que se anuncia. Entre 
as preocupações está a indagação sobre como se dará a reconfiguração das licenciaturas como cursos de formação de professores das diferentes disciplinas em nível superior.

Analisaremos as estratégias utilizadas nas DCNEM de 2012, que evidenciam aspectos da organização curricular e do lugar estabelecido para as disciplinas nas legislaçóes vigentes para o ensino médio que vão além da interdisciplinaridade. Com isso, desejamos contribuir para o debate que tem colocado apenas sobre ela um papel desestabilizador na organização curricular do ensino médio e, por conseguinte, na formação de professores.

Para esta análise consideraremos o conjunto de documentos relativos às duas DCNEM: o Parecer CNE/CEB no 5/2011 (BRASIL, 2012a) e a Resoluçâoo CNE/CEB no 2/2012 (BRASIL, 2012b), das DCNEM de 2012, e o Parecer CNE/CEB no 15/98 (BRASIL, 1998b) e a Resolução CNE/CEB no 3/1998 (BRASIL, 1998b), das DCNEM de 1998. Incluímos, também, a análise do Caderno IV da "Formação de professores do ensino médio", Etapa 1 (versão preliminar), que trata das áreas de conhecimento e integração curricular, material didático produzido no escopo do Pacto Nacional pelo Fortalecimento do Ensino Médio (RAMOS; FREITAS; PIERSON, 2013).

\section{A integração curricular como princípio}

A proposta de integração curricular já estava presente na LDB de 1996. Surgiu nos PCN do Ensino Fundamental na forma da transversalidade e pouco havia repercutido na organização curricular das escolas. Reapareceu nas DCNEM de 1998 como interdisciplinaridade. Porém, como vimos, também não repercutiu no ensino médio durante esse período. A pequena adesão a essas propostas é registrada na justificativa para a apresentação de uma nova DCNEM, que reafirma a integraçâo em novas bases.

O artigo 5 da Resoluçáo de 2012, relativo ao "Referencial legal e conceitual" pautado na LDB de 1996, apresenta as bases para o ensino médio:

Art. 50 - O Ensino Médio em todas as suas formas de oferta e organização, baseia-se em:

I - formação integral do estudante;

II - trabalho e pesquisa como princípios educativos e pedagógicos, respectivamente; 
III - educação em direitos humanos como princípio nacional norteador;

IV - sustentabilidade ambiental como meta universal;

V - indissociabilidade entre educaçáo e prática social, considerando-se a historicidade dos conhecimentos e dos sujeitos do processo educativo, bem como entre teoria e prática no processo de ensino-aprendizagem;

VI - integração de conhecimentos gerais e, quando for o caso, técnico-profissionais realizada na perspectiva da interdisciplinaridade e da contextualizaçáo;

VII - reconhecimento e aceitaçáo da diversidade e da realidade concreta dos sujeitos do processo educativo, das formas de produção, dos processos de trabalho e das culturas a eles subjacentes;

VIII - integração entre educação e as dimensóes do trabalho, da ciência, da tecnologia e da cultura como base da proposta e do desenvolvimento curricular. (BRASIL, 2012b, p. 2).

\section{Um eixo integrador}

Tomemos como ponto de partida o princípio VI do artigo $5^{\circ}$ da Resolução de 2012 (BRASIL, 2012b). Nele, a integração de conhecimentos no ensino médio deve ser realizada na perspectiva da interdisciplinaridade e da contextualização. Desde os documentos anteriores a interdisciplinaridade está sempre relacionada à contextualização.

No princípio VIII do artigo $5^{\circ}$ há a referência à integração entre educação e as dimensóes do trabalho, da ciência, da tecnologia e da cultura. Ou seja, afirma-se que essas dimensóes devem constituir um eixo integrador para os conhecimentos a serem ministrados (BRASIL, 2012b).

Há articulações importantes entre os outros princípios ${ }^{1}$. A começar pelo primeiro deles, a formação integral do estudante, presente na LDB de 1996 (BRASIL, 1996). Essa formação integral mostra-se como uma justificativa para a integração dos conhecimentos. Outra articulação está na afirmação da prevalência do trabalho e da pesquisa como princípios que antecedem a quaisquer outros, estabelecendo desdobramentos que vão repercutir sobre o que se entende por interdisciplinaridade e contextualização. Tanto que o Parecer de 
2011 afirma: "Como razão da formação específica, o trabalho aqui se configura também como contexto” (BRASIL, 2012a, p. 21).

A menção ao trabalho como eixo do processo educativo está presente na LDB de 1996, é tomada pelas DCNEM de 1998 na perspectiva do mercado e recebe centralidade nas DCNEM de 2012 na proposta de formação integral. "O trabalho é conceituado na sua perspectiva ontológica de transformação da natureza, como realização inerente ao ser humano e como mediação no processo de produção da sua existência" (BRASIL, 2012b, p. 2). Sua vinculação ao mundo capitalista, como emprego assalariado, também é considerada, de forma crítica e a ser problematizada (RAMOS; FREITAS; PIERSON, 2013).

A relação estabelecida entre os princípios é hierarquizante, mas eles se comunicam e se fortalecem mutuamente, visando contemplar o universo social dos jovens alunos e, ao mesmo tempo, propiciar o acesso a conhecimentos científicos integrados que sejam significativos para suas experiências.

O artigo 13 da Resolução de 2012 (BRASIL, 2012b), relativo à organizaçấo curricular nas escolas, orienta as unidades escolares a definir suas proposiçóes curriculares considerando cinco valores, já presentes no artigo $5^{\circ}$ da mesma, e que são tomados como conceitos e princípios:

I - as dimensóes do trabalho, da ciência, da tecnologia e da cultura como eixo integrador entre os conhecimentos de distintas naturezas, contextualizando-os em sua dimensão histórica e em relação ao contexto social contemporâneo. II - o trabalho como princípio educativo, para a compreensão do processo histórico de produção científica e tecnológica, desenvolvida e apropriada socialmente para a transformação das condiçôes naturais da vida e a ampliação das capacidades, das potencialidades e dos sentidos humanos. (BRASIL, 2012b, p. 4).

Nessa Resolução é enfatizado que o ensino médio deve oferecer diferentes formas de organizaçâo curricular, visando os princípios da diversidade e do trabalho, em que o universo profissional se constitui como contexto (BRASIL, 2012b). Desse modo, trabalho, ciência, tecnologia e cultura são dimensões da realidade que se afirmam como um dos caminhos para a integração dos conhecimentos curriculares (disciplinares ou não). Vejamos a seguir a constituição do espaço para a diversidade na organização curricular. 


\section{Base comum e parte diversificada}

Desde a LDB de 1996, passando pela DCNEM de 1998, afirma-se a necessidade de articulação entre uma base nacional comum e uma parte diversificada do currículo. As DCNEM de 2012 não fogem à regra, apesar de existir uma significativa diferença no entendimento da relação entre base comum e diversificada, ou seja, são formas de associar diversos conhecimentos (presentes na escola com uma organização disciplinar ou não). Nas atuais Diretrizes é a partir de uma base nacional comum, com componentes curriculares específicos, que se constitui uma parte diversificada, composta de acordo com as expectativas regionais e dos próprios alunos (BRASIL, 2012b, p. 2) 2). Compreendemos que essa organizaçáo se configura como uma das estratégias para a integraçáo curricular, tanto pela concepçáo de base comum quanto pelo investimento na consideração da diversidade como referência para a contextualizaçáo dos conhecimentos.

Nessas DCNEM surge como peculiaridade a constituição dos sujeitos do ensino médio como alunos diversos. O item 4 do Parecer (BRASIL, 2012a, p. 12), intitulado "Os sujeitos/estudantes do Ensino Médio", afirma a existência de juventudes, no plural, nas quais se encontram, além do jovem estudante com dedicação exclusiva ao curso do ensino regular, estudantes trabalhadores, da Educação de Jovens e Adultos (EJA), do ensino noturno, da educação especial, indígenas, do campo e quilombolas. A presença na escola brasileira de múltiplos alunos justifica a necessidade de uma parte diversificada, bem como a busca de significação para os conteúdos curriculares através da contextualização que leve em conta essa diversidade.

No que se refere à base nacional comum, nas DCNEM de 1998 havia, como vimos, três áreas de conhecimento: Linguagens, Códigos e suas Tecnologias, Ciências da Natureza, Matemática e suas Tecnologias e Ciências Humanas e suas Tecnologias. Agora, a ênfase nas tecnologias, uma das características daquele momento, é redimensionada. As tecnologias passam a fazer parte das dimensóes que constituem o eixo integrador do currículo, já mencionado (trabalho, ciência, tecnologia e cultura). Hoje, considerada a base nacional comum, o currículo do ensino médio é organizado em quatro áreas de conhecimento, a saber: Linguagens, Matemática, Ciências da Natureza e Ciências Humanas.

A organização curricular do ensino médio deve contemplar essas quatro áreas de conhecimento, "com tratamento metodológico que evidencie a 
contextualização e a interdisciplinaridade ou outras formas de interação e articulação entre diferentes campos de saberes específicos" (BRASIL, 2012a, p. 6). No parágrafo $2^{\circ}$ do Parecer de 2011, o documento ressalva:

A organização por áreas de conhecimento náo dilui nem exclui componentes curriculares com especificidades e saberes próprios construídos e sistematizados, mas implica no fortalecimento das relaçôes entre eles e a sua contextualização para apreensão e intervenção na realidade. (BRASIL, 2012a).

Dessa maneira, o arranjo dos componentes curriculares da base comum em áreas de conhecimento estabelece a perspectiva da integração curricular dentro dessas áreas. Para a manutenção das especificidades dos componentes curriculares se colocam duas ressalvas: eles permanecem desde que em relação com os demais (perspectiva da interdisciplinaridade) e devem ser contextualizados para apreensão e intervenção na realidade. Assim, reitera-se a vinculação do conhecimento disciplinar ao mundo do aluno, em sua diversidade, e afirma-se a necessidade de sua permanente relação com conhecimentos de outras áreas.

\section{A interdisciplinaridade como meta continuada}

Visando a meta de integração curricular estabelecida desde a LDB de 1996, a menção à interdisciplinaridade é sempre feita em conjunto com a necessidade de contextualização. Tal relação já ocorria na DCNEM de 1998, fruto da pretensão de que o ensino médio apresentasse aos alunos um conjunto de conhecimentos mais significativos. A significação aí evoca as vivências de cada um, ou seja, conhecimentos que tenham sentido para a vida. Essas vivências propiciariam a definição de temas integradores dos componentes curriculares. Assim, interdisciplinaridade e contextualização caminhariam juntas visando a integração curricular.

A interdisciplinaridade e contextualização foram propostas como princípios pedagógicos estruturadores do currículo para atender o que a lei estabelece quanto às competências de: vincular a educaçáo ao mundo do trabalho e à prática social; compreender os significados; ser capaz de continuar aprendendo; preparar-se para 
o trabalho e o exercício da cidadania; ter autonomia intelectual e pensamento crítico; ter flexibilidade para adaptar-se a novas condiçốes de ocupação; compreender os fundamentos científicos e tecnológicos dos processos produtivos; relacionar a teoria com a prática. (BRASIL, 1998a, p. 47).

A interdisciplinaridade e a contextualização são noçôes que merecem destaque, considerando a continuidade de um projeto e o valor atribuído a esses princípios pedagógicos. Como nosso foco está na interdisciplinaridade, buscamos reconhecer as permanências e, ao mesmo tempo, perceber diferenças de concepção sobre tais noçóes entre as DCNEM.

As DCNEM de 1998 afirmam: "[...] será principalmente na possibilidade de relacionar as disciplinas em atividades ou projetos de estudo, pesquisa e ação, que a interdisciplinaridade poderá ser uma prática pedagógica e didática adequada aos objetivos do ensino médio" (BRASIL, 1998a, p. 29). E apresentam diferentes possibilidades de compreensão sobre a mesma, a partir da ideia de diálogo entre as disciplinas, como no trecho abaixo:

[...] a relação entre as disciplinas tradicionais pode ir da simples comunicaçẫo de idéias até a integração mútua de conceitos diretores, da epistemologia, da terminologia, da metodologia e dos procedimentos de coleta e análise de dados. Ou pode efetuar-se, mais singelamente, pela constatação de como são diversas as várias formas de conhecer. (BRASIL, 1998a, p. 30).

Com tal compreensão, as DCNEM de 1998 atribuem aos professores, coordenadores pedagógicos e alunos a responsabilidade por definir os eixos integradores para a concretização da interdisciplinaridade e da contextualização:

É importante enfatizar que a interdisciplinaridade supóe um eixo integrador, que pode ser o objeto de conhecimento, um projeto de investigação, um plano de intervenção. Nesse sentido ela deve partir da necessidade sentida pelas escolas, professores e alunos de explicar, compreender, intervir, mudar, prever, algo que desafia uma disciplina isolada e atrai a atenção de mais de um olhar, talvez vários. (BRASIL, 1998a, p. 30). 
Já nas DCNEM de 2012, a interdisciplinaridade é justificada como parte de um projeto de formação integral dos alunos. No documento (BRASIL, 2012a), está presente uma definição de interdisciplinaridade recuperada das Diretrizes Curriculares Nacionais Gerais para a Educação Básica, o que evidencia a busca de coerência do Poder Executivo federal e do Conselho Nacional de Educação, no que se refere aos conceitos mobilizados e suas definições (Parecer CNE/CEB no 7/2010 e Resolução CNE/CEB no 4/2010):

A interdisciplinaridade pressupóe a transferência de métodos de uma disciplina para outra. Ultrapassa-as, mas sua finalidade inscreve-se no estudo disciplinar. Pela abordagem interdisciplinar ocorre a transversalidade do conhecimento constitutivo de diferentes disciplinas, por meio da ação didático-pedagógica mediada pela pedagogia dos projetos temáticos. (BRASIL, 2012a, p. 44).

O Caderno IV apresenta a interdisciplinaridade como uma necessidade na formação integral, diante da fragmentação constitutiva da organização disciplinar dos conhecimentos (RAMOS; FREITAS;PIERSON, 2013). Remete ao princípio epistemológico das DCNEM de 2012, que é a visão ampla da realidade pela integraçâo dos conhecimentos. Assim, sua pretensão epistemológica vai além do âmbito da integração das disciplinas escolares, visando uma forma específica de estabelecer essa integração.

Ao tomar como referência as DCNEM de 2012, as disciplinas escolares permanecem no ensino médio sob condiçóes, com a prevalência da integração a partir do tema do trabalho e do eixo integrador: trabalho, ciência, tecnologia e cultura. Já considerando o detalhamento do Parecer, prevalece a afirmação da necessidade de aprofundamento dos conceitos inerentes às disciplinas escolares, "já que cada uma se caracteriza por ter objeto próprio de estudo e método específico de abordagem" (BRASIL, 2012a, p. 43). O documento apresenta uma soluçáo para a definiçáo de caminhos a seguir entre a disciplina e a interdisciplinaridade, através de metodologia mista, em que há dois espaços e tempos:

Um, destinado ao aprofundamento conceitual no interior das disciplinas, e outro, voltado para as denominadas atividades integradoras. [...] com uma organização por disciplinas (recorte do real para aprofundar conceitos) 
e com atividades integradoras (imersão no real ou sua simulação para compreender a relação parte-totalidade por meio de atividades interdisciplinares). (BRASIL, 2012a, p. 43-44).

Sendo assim, a disciplina escolar mantém sua razão de ser no ensino médio, pois a especificidade de sua existência, objeto e método, permanece como um bem a considerar, alternadamente com a integração curricular. E é a manutenção dos limites disciplinares que configura o diálogo interdisciplinar.

\section{A diversidade dos componentes curriculares}

Vejamos agora o último ponto apresentado como uma estratégia para a integração curricular. A Resolução de 2012 evoca a LDB de 1996 no artigo 9o para apresentar os componentes curriculares obrigatórios - não unicamente disciplinas -, que podemos relacionar aos "saberes próprios construídos e sistematizados" (BRASIL, 2012b, p. 3). No artigo 14, elucida que os componentes curriculares que integram as áreas de conhecimento podem ser compreendidos como: "[...] disciplinas, sempre de forma integrada, ou como unidades de estudos, módulos, atividades, práticas e projetos contextualizados e interdisciplinares ou diversamente articuladores de saberes, desenvolvimento transversal de temas ou outras formas de organização" (BRASIL, 2012b, p. 6).

Assim, esclarece-se que, na perspectiva da Resoluçáo que sintetiza as DCNEM de 2012, não existe, para o ensino médio, a obrigatoriedade de organização dos conhecimentos de forma disciplinar. Ela é uma entre outras alternativas para a organização curricular. Ao mesmo tempo, as disciplinas continuam no horizonte de possibilidades, em um documento que pretende ser uma diretriz abrangente, que não define de forma fixa o que é o ensino médio e expressa o esforço de identificar diversas possibilidades de estruturaçáo da etapa final da educaçáo básica, levando em conta a diversidade de modalidades de Ensino Médio (EM) existentes: EM regular, EM integrado, EM EJA, e ainda a diversidade de alunos existentes - quilombolas, indígenas, jovens trabalhadores ou não.

Nesse sentido, vale chamar a atenção para as diversas denominaçóes presentes nos componentes curriculares destacados abaixo (mais ou menos relacionados a conhecimentos sistematizados), que evidenciam algumas dessas possibilidades: 
a) O estudo da Língua Portuguesa e da Matemática, o conhecimento do mundo físico e natural e da realidade social e política, especialmente do Brasil;

b) a Educaçẫo Física, integrada à proposta pedagógica da instituição de ensino, sendo sua prática facultativa ao estudante nos casos previstos em Lei;

c) o ensino da História do Brasil, que leva em conta as contribuiçóes das diferentes culturas e etnias para a formação do povo brasileiro, especialmente das matrizes indígena, africana e europeia;

d) o estudo da História e Cultura Afro-Brasileira e Indígena, no âmbito de todo o currículo escolar, em especial nas áreas de Educação Artística e de Literatura e História brasileiras;

e) a Filosofia e a Sociologia em todos os anos do curso; f) uma língua estrangeira moderna na parte diversificada, escolhida pela comunidade escolar, e uma segunda, em caráter optativo, dentro das disponibilidades da instituição. (BRASIL, 2012b, p. 3).

Vemos que há denominaçóes de estudo, conhecimento, ensino e nomes próprios de disciplinas como Filosofia, Sociologia e Educação Física, alargando sobremaneira os sentidos possíveis aos componentes curriculares. Essa amplitude apresenta implicaçóes diretas na organização escolar para além do currículo, como na distribuição do tempo e espaço escolar. Mais ainda, afeta a atuação dos professores já em exercício, que além de uma formação disciplinar já desenvolveram rotinas de trabalho na lógica da distribuição de tempos e espaços relativamente às aulas disciplinares, configuradas na cultura escolar ao longo de décadas. Além disso, afeta a formaçáo inicial dos professores, no sentido de oferecimento de disciplinas acadêmicas que possam ser traduzidas no ensino médio como estudo ou ensino, desvinculadas de uma disciplina escolar nos moldes atuais. Mais do que a proposta de interdisciplinaridade, tal amplitude reconfigura os conhecimentos disciplinares e as formas de seu ensino.

\section{A integração dos conhecimentos como perspectiva na formação profissional}

A ênfase na integraçáo dos conhecimentos como algo a alcançar que atravessa a LDB, duas diretrizes curriculares para o ensino médio e 
outras tantas regulamentaçóes publicadas com o intervalo de 14 anos vem despertando a atenção dos especialistas, pois evidencia uma tendência que não deve ser desconsiderada, partindo do Poder Executivo Federal. Para além da interdisciplinaridade no ensino básico, demonstra uma preocupação com as formas contemporâneas de produção do conhecimento.

$\mathrm{Na}$ Coordenação de Aperfeiçoamento de Pessoal de Nível Superior (CAPES) existe um tratamento prioritário para a questão da interdisciplinaridade, que pode ser percebido por meio dos encontros promovidos para discutir a questáo nas universidades brasileiras e entre áreas de conhecimento capitais para o avanço científico. A partir dos resultados do "Encontro Acadêmico Internacional Interdisciplinaridade no Ensino, Pesquisa e Extensão", realizado em 2012, o Fórum de Pró-Reitores de Pesquisa e Pós-Graduação (FOPROP) assumiu, em conjunto com a CAPES, o compromisso de discutir, propor e estabelecer medidas que possam contribuir para sua internalização e institucionalização no âmbito das universidades, bem como para sua adoçáo pelos órgáos de fomento brasileiros.

Entre os objetivos desses encontros estão: a identificação dos avanços e desafios na implementação da interdisciplinaridade no ensino, pesquisa e extensão, com base nos resultados dos Encontros Regionais; a indicação de estratégias e mecanismos para institucionalização da interdisciplinaridade nas universidades, nas agências de fomento, nos conselhos profissionais e nas entidades de representação científica; e a caracterização dos avanços obtidos e perspectivas da contribuição da interdisciplinaridade na construçấo do conhecimento, na formação acadêmica de novos perfis profissionais e na inserção social da universidade. Além disso, uma das 48 áreas de avaliação da CAPES é a Interdisciplinar. E na avaliação do Sistema Nacional de Pós-Graduação, a interdisciplinaridade é levada em consideração por cada área de conhecimento. Logo, não é um movimento só para a educação básica e não significa, de forma alguma, acabar com o que há de específico em cada ciência.

Sabe-se que os documentos oficiais dessa natureza são pactuados, expressando os acordos possíveis entre posiçóes diversas. Assim, se posiçóes se consolidam através de governos que se sucedem, devem ser consideradas como tendências a prevalecer. Segundo Lopes (2008), parte dessa continuidade é explicada pela permanência de uma mesma comunidade epistêmica no centro de decisões que organiza os documentos oficiais. Considerando a continuidade de projetos entre os governos de Luis Inácio Lula da Silva e Dilma Rousseff, tais 
propostas encontram-se, como visto na primeira parte deste texto, articuladas a outras tantas ações de governo, como o desenvolvimento do Pacto Nacional pelo Fortalecimento do Ensino Médio.

Segundo análise de Mohelecke (2012), as novas DCNEM pretendem corrigir alguns desvios apontados entre os intelectuais da educação que se ocuparam criticamente das DCNEM de 1998. Entre essas alteraçóes, podemos vislumbrar a busca de uma integração curricular, como apresentada aqui, com o eixo na articulação entre base nacional e parte diversificada, com a ênfase na interdisciplinaridade e na reestruturação dos componentes curriculares.

As novas DCNEM também visam obter mais adesão por parte das escolas como componentes dos sistemas de ensino em relação aos princípios estabelecidos anteriormente e mantidos, inclusive, em outras legislaçóes educacionais (MOHELECKE). Para alcançar essa adesão, no espaço de eventuais contradiçóes dos pactos estabelecidos entre concepçóes educacionais distintas, o Ministério da Educação estabelece, neste momento, o Pacto Nacional pelo Fortalecimento do Ensino Médio. O trabalho de formação continuada anunciado pelo ministro da Educação pode contribuir para esse processo. Porém, estão pendentes outras açoóes e definiçóes, não apenas no âmbito federal, mas também estadual, já que é nos sistemas estaduais que se realiza predominantemente tal ensino.

No que se refere às escolas, são necessárias mudanças estruturais, como na redefinição de espaços para o funcionamento escolar e para o trabalho docente. A divisão de tempos na organização das aulas e o tempo dedicado ao planejamento do professor mostram-se ultrapassados, já que a pretensão é reestruturar as formas de conhecer e de apresentar o conhecimento. Do mesmo modo, a alocação das aulas em espaços exclusivos, um professor para cada aula e para cada turma. Dessa maneira, os sistemas estaduais deverão passar por alteraçóes que propiciem a abertura da cultura escolar a novas formas de significar o conhecimento disciplinar. Entre essas mudanças está a criação de espaços e tempos de planejamento e de realização de projetos conjuntos nas escolas, entre professores de disciplinas e áreas diferentes.

Os sujeitos do ensino médio não são apenas os alunos em sua diversidade. São também os professores de diferentes geraçôes que atuam na escola. Eles possuem autonomia relativa para promover mudanças em suas salas de aula. Para que os professores considerem a possibilidade de investir em um novo ensino médio, precisam vislumbrar na escola um novo espaço e tempo, desamarrado 
desses e de outros constrangimentos para o novo.

Considerando as diferentes possibilidades de organizaçáo dos conhecimentos, em disciplinas, atividades e estudos, coloca-se o desafio de oferecer uma base sólida de formação disciplinar, que se abra para o diálogo interdisciplinar nas instituiçóes formadoras de professores para a educação básica. Mas, essa é uma outra história a ser escrita.

\section{Notas}

${ }^{1}$ De interesse para a discussáo proposta aqui, os Referenciais do DCNEM oferecem a conceituaçáo pretendida para os diferentes termos mencionados nos princípios: " $\$ 1^{\circ} \mathrm{O}$ trabalho é conceituado na sua perspectiva ontológica de transformação da natureza, como realização inerente ao ser humano e como mediação no processo de produção da sua existência. $\$ 2^{\circ}$ A ciência é conceituada como o conjunto de conhecimentos sistematizados, produzidos socialmente ao longo da história, na busca da compreensão e transformação da natureza e da sociedade. $\$ 3^{\circ}$ A tecnologia é conceituada como a transformaçáo da ciência em força produtiva ou mediação do conhecimento científico e a produção, marcada, desde sua origem, pelas relaçóes sociais que a levaram a ser produzida. $\$ 4^{\circ} \mathrm{A}$ cultura é conceituada como o processo de produçáo de expressôes materiais, símbolos, representaçóes e significados que correspondem a valores éticos, políticos e estéticos que orientam as normas de conduta de uma sociedade" (BRASIL, 2012b, p. 2).

${ }^{2}$ A base comum não é entendida como currículo mínimo nos documentos legais, significado presente na legislação de 1971.

\section{REFERÊNCIAS}

BRASIL. Lei n ${ }^{\circ}$ 9.394, de 20 de dezembro de 1996. Estabelece as diretrizes e bases da educação nacional. Diário Oficial da União, Brasília, DF, 23 dez. 1996.

BRASIL. Ministério da Educação. Conselho Nacional de Educação. Câmara de Educação Básica. Parecer CEB no 15/98, de 1 de junho de 1998.

Diretrizes Curriculares Nacionais para o Ensino Médio. Diário Oficial da União, Brasília, DF, 26 jun. 1998a. 
BRASIL. Ministério da Educação. Conselho Nacional de Educação. Câmara de Educação Básica. Resolução CEB nº 3, de 26 de junho de 1998. Institui as Diretrizes Curriculares Nacionais para o Ensino Médio. Diário Oficial da União, Brasília, DF, 5 ago. 1998b.

BRASIL. Secretaria de Educação Média e Tecnológica. Parâmetros curriculares nacionais: ensino médio. Brasília: MEC/SEMTEC, 1999.

BRASIL. Secretaria de Educação Média e Tecnológica. PCN+ Ensino Médio: orientações educacionais complementares aos Parâmetros Curriculares Nacionais. Brasília: MEC/SEMTEC, 2002.

BRASIL. Secretaria de Educação Básica. Orientaçôes Curriculares do Ensino Médio. Brasília: MEC/SEB, 2004.

BRASIL. Ministério da Educação. Conselho Nacional de Educação. Câmara de Educação Básica. Parecer CEB no 5/2011, de 5 de maio de 2011. Diretrizes Curriculares Nacionais para o Ensino Médio. Diário Oficial da Uniāo. Brasília, DF, 24 jan. 2012a.

BRASIL. Ministério da Educação. Conselho Nacional de Educação. Câmara de Educação Básica. Resolução no 2, 30 de janeiro de 2012. Define Diretrizes Curriculares Nacionais para o Ensino Médio. Diário Oficial da União, Brasília, DF, 31 jan. 2012b.

BRASIL. MEC. Portaria ministerial no 1.140, de 22 de novembro de 2013. Institui o Pacto Nacional pelo Fortalecimento do Ensino Médio e define suas diretrizes gerais, forma, condições e critérios para a concessão de bolsas de estudo e pesquisa no âmbito do ensino médio público, nas redes estaduais e distrital de educação. Diário Oficial da União, Brasília, DF, 9 dez. 2013.

LOPES, Alice Casemiro. Políticas de integraçâo curricular. Rio de Janeiro: EDUERJ, 2008.

MERCADANTE, Aloízio. Pacto Nacional pelo Fortalecimento do Ensino Médio. Brasília, DF, 25 nov. 2013. Pronunciamento Oficial. Disponível em: $<\underline{\text { http:// }}$ www.youtube.com/watch?v=CBJA0sznNHM>. Acesso em: $20 \mathrm{dez} .2013$.

MOEHLECKE, Sabrina. O ensino médio e as novas diretrizes curriculares nacionais: entre recorrências e novas inquietaçōes. Revista Brasileira de Educação, Rio de Janeiro, v. 17, n. 49, p.39-58, jan./abr. 2012.

RAMOS, Marise Nogueira; FREITAS, Denise de; PIERSON, Alice Helena Campos. Formação de professores do ensino médio, etapa I - caderno IV: áreas de conhecimento e integração curricular. Curitiba, PR: MEC/UFPR, 2013. 


\section{Le lycée brésilien en question: l'intégration des programmes et la formation des enseignants}

\section{Resume}

Cet article examine les propositions de reformulation de l'enseignement au niveau de Lycée au Brésil, s'adressant à l'intégration du programme d'études proposé comme un problème pour la mise en œuvre d'une nouvelle École Secondaire. L'intégration du programme d'études a été menée depuis les années 1990, à partir des directrices, des consultations et de la Loi de Directrices et Bases elle-même, pour atteindre les nouvelles Lignes Directrices du Programme National d'Enseignement Secondaire de 2012. Le texte poursuit la route de la construction de l'intégration curriculaire comme un objectif et les notions clés qui la soutiennent. Il comprend que l'intégration des programmes voulus, ainsi que ses bases, nécessitent certaines conditions qui permettent des changements dans la formation initiale et continue des enseignants, entre eux les changements structurels dans les temps et les espaces de l'école et de l'enseignant, ainsi que une réflexion consistante et critique sur cet ensemble d'idées dans le cadre des institutions de formation des enseignants, conduisant à la création de nouveaux cours pour cette formation.

\section{Discussing the Brazilian high school: curriculum integration and teacher training}

\section{Abstract}

This article analyses the proposals to redesign high-school education in Brazil. It addresses the curricular integration proposal as an issue in the process of implementing a new high-school education. Curricular integration has been pursued since the first documents of high school organization were written in the 1990's - guidelines, opinions, and the LDB (National Education Guidelines and Foundations) itself until reaching the new National High School Curricular Guidelines, enforced in 2012. This article describes the process of building an integrated curriculum as a goal and the main concepts that support this integration. The curricular integration desired, as well as its foundations, would require changes in the initial and continuing education of teachers such as structural changes in time and space at school and for teachers. It would also require a consistent and critical reflection upon this set of ideas in teacher-training institutions in order to design new courses for teachers.

\section{Keywords: High School.} Interdisciplinarity. Teacher Training.

Mots-clés: Lycée. L'interdisciplinarité. Formation des enseignants. 


\section{Helenice Aparecida Bastos Rocha}

E-mail: helarocha@gmail.com

\section{Marcelo de Souza Magalhães}

E-mail: marcelosmagalhaes@hotmail.com

Recebido em: 23/1/2014

Versão final: $17 / 3 / 2014$

Aprovado em: 20/3/2014 